\title{
Crescimento e teores relativos de clorofila em plantas de girassol suplementadas com algas mistas - Hypnea pseudomusciformis ou Ulva fasciata
}

\author{
Paulo Ovídio Batista de BRITO ${ }^{1}$, Gabriela de Sousa FERREIRA¹, Francisco Ícaro Carvalho ADERALDO', \\ Joana D'arck Farias BRAGA¹, Janacinta Nogueira de SOUZA¹, Franklin Aragão GONDIM ${ }^{1 *}$
}

${ }^{1}$ Instituto Federal de Educação, Ciência e Tecnologia do Ceará, Maracanaú, CE, Brasil. (Orcid: 0000-0001-8978-8241; 0000-0002-3778-326X; 0000-0001-6834-2160; 0000-0003-3072-6243; 0000-0001-8495-3017; *) *E-mail: aragaofg@yahoo.com.br (Orcid: 0000-0002-7168-2358)

Recebido em 15/10/2019; Aceito em 03/08/2020; Publicado em 28/08/2020.

\begin{abstract}
RESUMO: O trabalho objetivou analisar os efeitos da utilização das algas Hypnea psendomusciformis, Ulva fasciata, e de algas mistas coletadas na Praia do Pacheco, Caucaia-CE sobre o crescimento de girassol (Helianthus annuus L.) avaliando-se: variáveis de crescimento e teores relativos de clorofila. O trabalho foi conduzido em casa de vegetação. As sementes de girassol foram semeadas em baldes de plástico com capacidade para cinco litros. O experimento foi dividido em oito tratamentos: areia (100\% do volume em areia); areia $+100 \%$ da recomendação de nitrogênio $(\mathrm{RN})$ em húmus; $100 \%$ da $\mathrm{RN}$ em algas mistas, $50 \%$ da $\mathrm{RN}$ em algas mistas; $100 \%$ da RN em Hypnea pseudomusciformis, 50\% da RN em Hypnea pseudomusciformis, $100 \%$ da RN em Ulva fasciata e $50 \%$ da RN em Ulva fasciata. A utilização de algas arribadas ocasionou melhoria nas variáveis de crescimento analisadas em relação às plantas crescendo em substrato com areia ou areia + húmus. Os melhores resultados foram observados a 50\% da RN em algas mistas. Dessa forma, a utilização de algas arribadas como fertilizantes apresentou-se como uma alternativa viável, gerando diminuição dos custos de produção.
\end{abstract}

Palavras chave: Helianthus annuus L.; fertilização orgânica; macroalgas.

\section{Growth and relative chlorophyll levels in sunflower plants supplemented with mixed algae - Hypnea pseudomusciformis or Ulva fasciata}

\begin{abstract}
The work's aim was to analyze the effects of the use of Hypnea psendomusciformis, Ulva fasciata, and mixed algae, collected at Pacheco Beach, Caucaia-CE on sunflower (Helianthus annuus L.) plants evaluating: growth variables and relative chlorophyll levels. The work was conducted under greenhouse conditions. Sunflower seeds were sown in five-liter plastic buckets. The experiment was divided in eight treatments: sand $(100 \%$ of the volume in sand); sand $+100 \%$ of nitrogen recommendation (NR) in humus; $100 \%$ of NR in mixed algae, $50 \%$ of NR in mixed algae; $100 \%$ of NR in Hypnea psendomusciformis, $50 \%$ of NR in Hypnea pseudomusciformis, 100\% of NR in Ulva fasciata and 50\% of NR in Ulva fasciata. The use of "arribadas algae" caused improvement in plant growth variables analyzed in comparison to plants growing on sand or sand + humus substrate. The best results were observed at 50\% of NR in mixed algae. Thus, the use of "arribadas algae" as fertilizers presented itself as a viable alternative, generating reduction of production costs.

Key words: Helianthus annuus L.; organic fertilization; macroalgae.
\end{abstract}

\section{INTRODUÇÃO}

As algas podem ser uni ou multicelulares e apresentar formas macroscópicas representadas pelas divisões Chlorophyta, (algas verdes), Rhodophyta (algas vermelhas) e Phaeophyceae (algas pardas). Por comporem um grupo heterogêneo e possuírem a capacidade fotossintetizante, ocupam todos os meios que ofereçam luz, nutrientes e umidade suficientes. Situam-se desde o fundo de águas costeiras rasas até zonas marítimas de até 180 metros de profundidade (ADAIKALARAJ et al., 2012).

As macroalgas marinhas produzem uma série de metabólitos primários e secundários, estes últimos, envolvidos principalmente em funções ecológicas, diferentes processos e dinâmicas funcionais que podem acarretar na conquista e adaptação a novos ambientes. (PEDRINI et al., 2010).

O Brasil é uma região considerada rica em diversidade de macroalgas marinhas. Podem ser encontradas em todo o litoral, sendo a região Nordeste do Brasil a de maior diversidade e abundância, principalmente em áreas de substrato rochoso e águas mais transparentes. Em determinados períodos, o acúmulo de algas na faixa areia é mais intenso, deixando as praias pouco atrativas para o turismo. Algas marinhas que se desprendem de seus substratos, são carreadas por ondas e correntes marinhas e se acumulam na faixa de areia, denominadas de "algas arribadas". A maior parte desta biomassa não é aproveitada pela população. Tendo em vista o alto valor nutricional, há grande potencial para o aproveitamento comercial (ARAÚJO, 2017).

As algas arribadas podem ser utilizadas como complemento para a fertilização de solos e também como substratos para atividades agrícolas, pois possuem nutrientes essenciais como o nitrogênio (N). Esse elemento é um dos fatores limitantes no crescimento de plantas, sendo necessário para a formação de biomoléculas importantes, 
como ATP, NADH, NADPH, clorofila e proteínas (BREDEMEIER; MUNDSTOCK, 2000)

A Praia do Pacheco, localizada no município de CaucaiaCE, Brasil região metropolitana de Fortaleza, apresenta acúmulo de algas arribadas na faixa de areia (Figura 1).

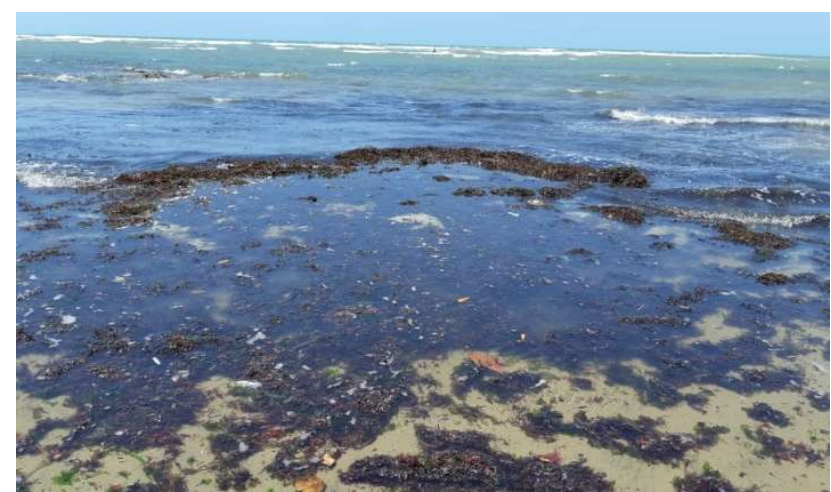

Figura 1. Vista parcial das algas arribadas da Praia do Pacheco, Caucaia, Ceará.

Figure 1. Partial view of arribadas algae of the Pacheco Beach, Caucaia, Ceará.

$\mathrm{Na}$ área de estudo identificou-se grande variedade de táxons, destacando-se dois pelo grande volume em relação às demais: Hypnea psendomusciformis e Ulva fasciata.

A

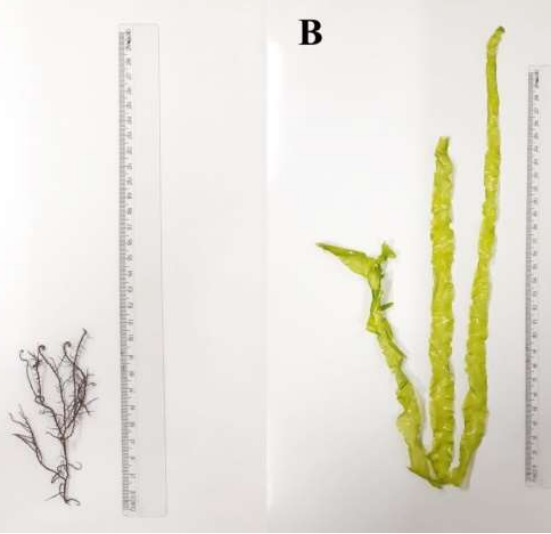

Figura 2. (A) Hypnea psendomusciformis e (B) Ulva fasciata.

Figure 2. (A) Hypnea psendomusciformis e (B) Ulva fasciata.

A Hypnea pseudomusciformis (Figura 2A), é uma macroalga vermelha, com ampla incidência nas costas tropicais e subtropicais ao redor do mundo, possui grande importância econômica como fonte de carragenina para produção industrial (NAUER et al., 2015).

A Ulva fasciata (Figura 2B) é uma espécie utilizada em diversos setores industriais, por possuir propriedades nutricionais, terapêuticas, antioxidante e antibacteriana. (SHAO et al., 2017). Possui resistência em áreas com luz intensa, alta concentração de oxigênio e a agentes infecciosos. É comumente encontrada em áreas costeiras, onde recebe a denominação popular de "alface do mar" (LAKSHMI et al., 2018).

É comum que ocorra a remoção das algas arribadas para um posterior descarte por empresas de limpeza urbana. No entanto, essa remoção não ocorre em toda faixa de areia do litoral cearense. Deste modo, devido à importância econômica, ecológica e à riqueza de nutrientes, foi analisada a utilização das espécies de macroalgas locais para a fertilização de plantas de girassol.
A fim de verificar a viabilidade da utilização das algas arribadas para produção de substratos para plantas, optou-se como material vegetal a planta de girassol (Helianthus annuus L.). A cultura expressa características desejáveis sob o ponto de vista agronômico, como curto ciclo de vida, elevada produtividade, qualidade e rendimento em óleo, sendo assim um constituinte de sistemas de produção de grãos e biodiesel (ARAÚJO et al., 2012).

O trabalho objetivou analisar os efeitos da utilização das algas Hypnea pseudomusciformis, Ulva fasciata, e de algas mistas coletadas na Praia do Pacheco, Caucaia-CE sobre o crescimento de plantas de girassol (Helianthus annuus L.) avaliando-se: variáveis de crescimento e teores relativos de clorofila.

Considerou-se como algas mistas o conjunto de algas presentes no local do estudo sem realizar nenhum tipo de triagem, constituindo-se predominantemente por algas vermelhas.

\section{MATERIAL E MÉTODOS}

O trabalho foi conduzido em casa de vegetação localizada no Instituto Federal de Educação Ciência e Tecnologia (IFCE) Campus Maracanaú, Ceará, Brasil, entre 01 e 20 de dezembro de 2018.

Foram coletadas amostras de algas arribadas de forma manual na Praia do Pacheco, Caucaia-CE, Brasil. A coleta ocorreu no dia 08 de outubro de 2018 , entre as 10:00h e 12:00h com maré $0,0 \mathrm{~m}$ e lua minguante (BRASIL, 2019). Os valores de maré foram obtidos na tábua de marés do Porto do Pecém-Ce.

As algas foram lavadas em água corrente de abastecimento. Posteriormente, encaminhadas ao Laboratório de Bioquímica e Fisiologia Vegetal do IFCE, Campus Maracanaú, para secagem em estufa de circulação forçada de ar a $80^{\circ} \mathrm{C}$, por aproximadamente $12 \mathrm{~h}$, até que a massa estivesse completamente seca, sem a presença de água ou qualquer forma de humidade. Após a secagem, o material foi triturado fazendo-se uso de almofariz e pistilo. Após esse procedimento, amostras de material de cada uma das espécies de maior quantidade, Hypnea pseudomusciformis, Ulva fasciata e uma amostra das algas arribadas não separadas foram encaminhadas para análise no Laboratório de Solos/Água da Universidade Federal do Ceará para a determinação de nitrogênio total $(\mathrm{N})$, conforme a metodologia de Malavolta et al. (1997) (Tabela 1). Os valores foram empregados nos cálculos de materiais acrescidos aos substratos. Para o tratamento contendo húmus de minhoca, os dados foram cedidos pelo fabricante Fértil Vida Produtos Agrícolas LTDA. As algas foram lavadas em água corrente de abastecimento. Posteriormente, encaminhadas ao Laboratório de Bioquímica e Fisiologia Vegetal do IFCE, Campus Maracanaú, para secagem em estufa de circulação forçada de ar a $80^{\circ} \mathrm{C}$, por aproximadamente $12 \mathrm{~h}$, até que a massa estivesse completamente seca, sem a presença de água ou qualquer forma de humidade. Após a secagem, o material foi triturado fazendo-se uso de almofariz e pistilo. Em seguida, amostras de material de cada uma das espécies de maior quantidade, Hypnea pseudomusciformis, Ulva fasciata e uma amostra das algas arribadas não separadas (algas mistas) foram encaminhadas para análise no Laboratório de Solos/Água da Universidade Federal do Ceará para a determinação de nitrogênio total $(\mathrm{N})$, conforme a metodologia de Malavolta et al. (1997) (Tabela 1). Os valores 
foram empregados nos cálculos de materiais acrescidos aos substratos. Para o tratamento contendo húmus de minhoca, os dados foram cedidos pelo fabricante Fértil Vida Produtos Agrícolas LTDA.

Tabela 1. Quantidade de nitrogênio total presente nas amostras de Hypnea psendomusciformis, Ulva fasciata, algas mistas e húmus de minhoca comercial.

Table 1. Quantity of total nitrogen presente in the samples of Hypnea pseudomusciformis, Ulva fasciata, mixed algae and earthworm humus.

\begin{tabular}{cc}
\hline Amostra & Nitrogênio $(\mathrm{g} / \mathrm{Kg})$ \\
\hline Hypnea pseudomusciformis & 45,6 \\
Ulva fasciata & 45,1 \\
Algas mistas & 39,8 \\
Húmus de minhoca & 40 \\
\hline
\end{tabular}

As sementes de girassol (cultivar BRS 323 cedidas pela Embrapa Produtos e Mercado) foram semeadas em baldes de plástico com volume de cinco litros, contendo: 1) 100\% (em volume) de Areia; 2) Areia $+100 \%$ da recomendação de nitrogênio (RN) em húmus de minhoca (seguindo-se recomendação da cultura de $80 \mathrm{~kg}$ de N.ha-1); 3) Areia + $100 \%$ da (RN) em macroalgas mistas; 4) Areia $+50 \%$ da (RN) em macroalgas mistas; 5) Areia $+100 \%$ da (RN) com Hypnea pseudomusciformis; 6) Areia $+50 \%$ da (RN) com Hypnea pseudomusciformis; 7) Areia $+50 \%$ da (RN) com Ulva fasciata; 7 ) Areia $+100 \%$ da $(\mathrm{RN})$ com Ulva fasciata. Os tratamentos foram irrigados a $80 \%$ da capacidade de campo.

Foram realizadas medições dos teores relativos de clorofila, número de folhas, altura das plantas, diâmetro dos caules e massa seca aos 20 dias após semeadura (DAS). A massa seca foi determinada após secagem em estufa a $80{ }^{\circ} \mathrm{C}$ até atingir material com massa constante. Mensurou-se a parte aérea constituída por folhas + pecíolos + caules; as raízes e a massa seca total (parte aérea + raízes).

Os teores relativos de clorofila (Índice SPAD) foram medidos na primeira folha completamente expandida a contar do ápice, foram realizadas três leituras por folha, (no limbo foliar), utilizando-se o aparelho Chlorophyll Meter SPAD-502. Os diâmetros dos caules foram medidos através de paquímetro, o número de folhas por contagem manual e a altura da parte aérea através de uma régua, medindo-se da base do caule até a inserção da última folha completamente expandida. Os diâmetros dos caules foram medidos através de paquímetro, o número de folhas por contagem manual e a altura da parte aérea através de uma régua, medindo-se da base do caule até a inserção da última folha completamente expandida.

O experimento foi montado em delineamento inteiramente casualizado (DIC), com oito tratamentos; descritos acima e cada um contendo oito repetições. Cada repetição constituiu-se de um vaso com três plantas. Os dados de cada coleta foram submetidos à análise de variância (ANOVA) e as médias comparadas pelo teste de Tukey $(P \leq$ 0,05) através do programa Sigma Plot 11.0.

\section{RESULTADOS}

Na Figura 3 observa-se as plântulas aos 20 dias após semeadura. Observou-se o maior crescimento dos grupos contendo algas em relação aos grupos areia e areia + húmus.

Para altura das plantas (Figura 4A), os maiores resultados foram verificados nos grupos suplementados com algas mistas, que apresentaram valores médios próximos de $12 \mathrm{~cm}$.
Esse valor foi 13,7\% superior que os grupos húmus e Hypnea $50 \%$ da RN, que apresentou valor médio de $10,6 \mathrm{~cm}$, e $32,2 \%$ superior que os demais grupos, que apresentaram valores médios próximos a $9,3 \mathrm{~cm}$.

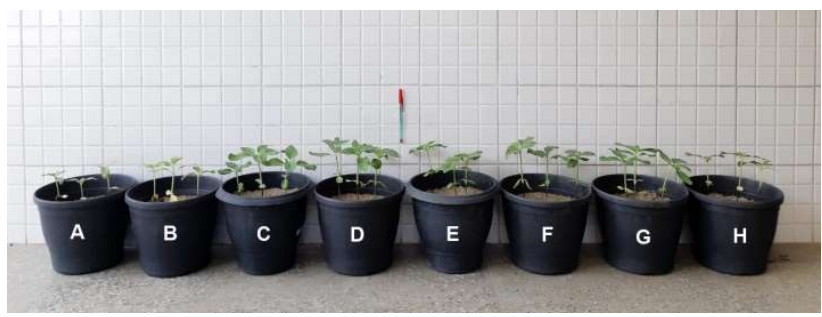

Figura 3. Plantas de girassol aos 20 dias após a semeadura em substratos contendo: (A) areia; (B) húmus a 100\% da recomendação de nitrogênio - RN; (C) algas mistas a $100 \%$ da RN; (D) algas mistas a $50 \%$ da RN; (E) Hypneapsendomusciformis a 100\% da RN; (F) Hypnea pseudomusciformis a $50 \%$ da RN; (G) Ulva fasciata $100 \%$ da RN; (H) Ulva fasciata a $50 \%$ da RN.

Figure 3. Sunflower plants at 20 days after sowing on substrates containing: (A) sand; (B) humus at 100\% of the nitrogen recommendation - NR; (C) 100\% mixed algae of NR; (D) mixed algae at $50 \%$ of NR; (E) Hypnea psendomusciformis at $100 \%$ of NR; (F) Hypnea psendomusciformis at $50 \%$ of NR; (G) Ulva fasciata $100 \%$ of NR; (H) Ulva fasciata at $50 \%$ of NR.

Para o diâmetro dos caules (Figura 4B), os maiores valores também foram para os grupos suplementados com algas mistas, apresentando valores médios próximos de 3,4 $\mathrm{mm}$. Esse resultado foi $9 \%$ maior que os grupos suplementados com Hypnea, que apresentaram valores médios de $3,1 \mathrm{~mm}, 20 \%$ maior que o grupo suplementado com Ulva a $100 \%$ da RN, que atingiu a média de $2,8 \mathrm{~mm}$ e $36 \%$ superior aos demais grupos.

Para o número de folhas (Figura 4C), os maiores valores foram para os grupos suplementados com algas mistas e para o grupo suplementado com Hypnea a $100 \%$ da $\mathrm{RN}$, que atingiram valores médios de 9,4 folhas por planta, sendo esse valor $36,8 \%$ superior aos demais grupos, que atingiram valores próximos de 7 folhas por planta.

Para teores relativos de clorofila (Figura 4D), o padrão foi o mesmo, onde os maiores valores foram para os grupos suplementados com algas mistas, com valores médios próximos de 35 (índice SPAD). Isso representa que o valor foi $10 \%$ maior que aqueles apresentados nos grupos suplementados com Hypnea e Ulva, e 45\% superior aos grupos areia e húmus.

Para massa seca da parte aérea (Figura 5A), os maiores valores foram para os grupos das algas mistas juntamente com o grupo Hypnea a $100 \%$ da $\mathrm{RN}$, com médias próximas a $0,87 \mathrm{~g}$. o segundo melhor resultado foi para o grupo Hypnea a $50 \%$ da RN, com valor de $0,76 \mathrm{~g}$, seguido pelo grupo Ulva a $100 \%$ da $\mathrm{RN}$, com valor de $0,60 \mathrm{~g}$. Por último, o grupo de menor destaque foi formado pelos grupos areia, húmus e Ulva a $50 \%$ da $\mathrm{RN}$, com médias próximas a $0,38 \mathrm{~g}$. Quando comparados os maiores resultados (mista a $100 \%$, mista a $50 \%$, e Hypnea a $100 \%$ da RN) com os menores (areia, húmus e Ulva a $50 \%$ da $\mathrm{RN}$ ) observou-se um aumento de $128 \%$.

Para massa seca da raiz (Figura 5B) o resultado mais expressivo foi para o grupo mista a $50 \%$ da $\mathrm{RN}$, com o valor de $0,29 \mathrm{~g}$, seguido pelos tratamentos mista a $100 \%$ da $\mathrm{RN}$, Hypnea a $50 \%$ da RN, e Ulva a $50 \%$ da RN, com valor médio de $0,24 \mathrm{~g}$, logo após os tratamentos Hypnea e Ulva a $100 \%$ da $\mathrm{RN}$, com valor médio de $0,20 \mathrm{~g}$, o por último os tratamentos 
húmus e areia, com valores de $0,15 \mathrm{~g}$ e $0,10 \mathrm{~g}$ respectivamente. Ao comparar o tratamento de maior expressão (mista a 50\% da $\mathrm{RN}$ ) com o tratamento areia, constatou-se que o resultado é quase três vezes maior.

A massa seca total (Figura 5C), teve o resultado mais expressivo nos tratamentos suplementados com algas mistas (100 e $50 \%$ da $\mathrm{RN}$ ), com valor médio de $1,12 \mathrm{~g}$, seguido pelos tratamentos suplementados com Hypnea (100 e 50\% da RN), com valor médio de $1 \mathrm{~g}$, logo após, o tratamento Ulva a 100\% da $\mathrm{RN}$, com média de $0,8 \mathrm{~g}$. Os tratamentos húmus e Ulva a $50 \%$ da $\mathrm{RN}$ apresentaram valores menos expressivos, com médias próximas a $0,6 \mathrm{~g}$, sendo superior apenas ao tratamento areia, que teve média de $0,42 \mathrm{~g}$. Assim, os tratamentos com algas mistas foram 166\% superiores à areia.

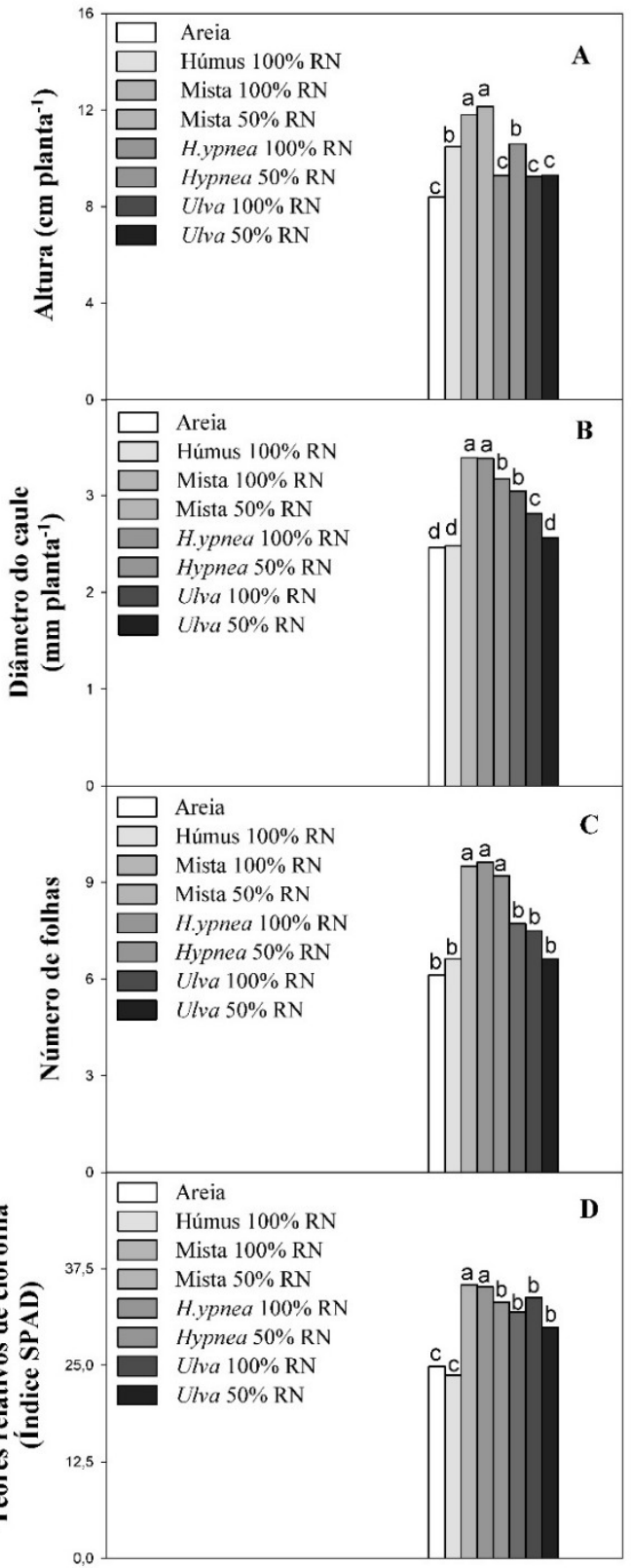

Figura 4. (A) Altura das plantas, (B) Diâmetro dos caules, (C) Número de folhas e (D) Teores relativos de clorofila em plântulas de girassol aos 20 dias após semeadura suplementada com húmus de minhoca, algas mistas, Hypnea pseudomusciformis ou Ulva fasciata a 50 ou $100 \%$ da recomendação de nitrogênio (RN). As barras representam os valores das médias de 8 repetições e letras diferentes indicam diferenças estatísticas de acordo com teste de Tukey a $5 \%$ de probabilidade.
Figure 4. (A) Plant height, (B) Stem diameter, (C) Number of leaves and (D) Relative chlorophyll content in sunflower seedlings at 20 days after sowing supplemented with earthworm humus, mixed algae, Hypnea psendomusciformis or Ulva fasciata at 50 or $100 \%$ of the nitrogen recommendation (NR). The bars represent the mean values of 8 repetitions and different letters indicate statistical differences according to Tukey test at $5 \%$ probability.

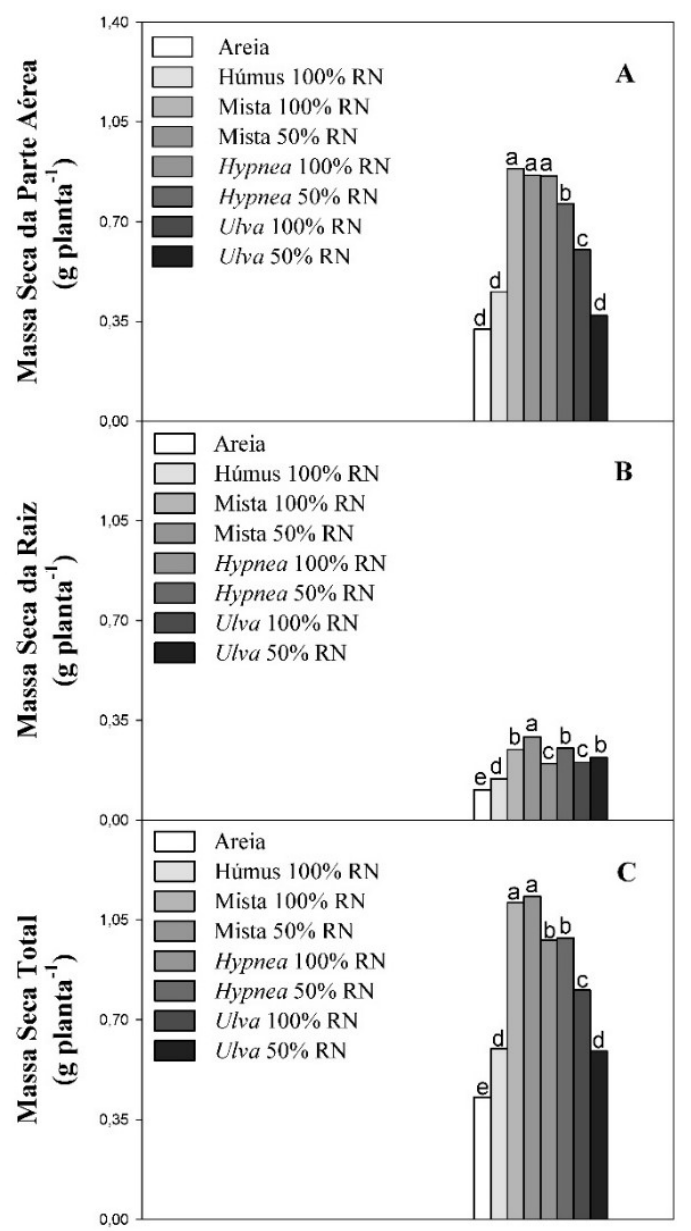

Figura 5. (A) Massa seca da parte aérea, (B) da raiz e (C) total de plantas de Girassol aos 20 dias após semeadura suplementadas com húmus de minhoca, algas mistas, Hypnea pseudomusciformis ou Ulva fasciata a 50 ou $100 \%$ da recomendação de nitrogênio (RN). As barras representam os valores das médias de 8 repetições e letras diferentes indicam diferenças estatísticas de acordo com teste de Tukey a $5 \%$ de probabilidade.

Figure 5. (A) Shoot dry mass, (B) root and (C) total Sunflower plants at 20 days after sowing supplemented with worm humus, mixed algae, Hypnea psendomusciformis or 50 or $100 \%$ Ulva fasciata nitrogen recommendation (NR). The bars represent the mean values of 8 repetitions and different letters indicate statistical differences according to Tukey test at 5\% probability.

\section{DISCUSSÃO}

Os tratamentos suplementados com Hypnea pseudomusciformis e com Ulva fasciata apresentaram resultados superiores ou semelhantes ao tratamento húmus, apresentando-se viáveis para a nutrição vegetal. No entanto, para todas as variáveis analisadas, os resultados mais expressivos foram para os tratamentos suplementados com macroalgas mistas, não havendo diferenças estatísticas entre os tratamentos suplementados a 50 e a $100 \%$ da recomendação de nitrogênio.

Semelhantemente, o trabalho realizado por Alobwede et al. (2019) verificou os efeitos positivos da utilização de micro 
e macroalgas como fonte de nutrientes para o solo em condições de casa de vegetação e de campo.

Já o trabalho realizado por Zhou et al. (2019) testou o efeito do fertilizante líquido de algas marinhas na produção e qualidade de Capsicum annuиm L. Como resultado, sugeriu-se que o composto utilizado poderia servir como um biofertilizante alternativo, pois apresentou custo-benefício positivo capaz de entregar benefícios econômicos e ambientais substanciais para o agricultor.

Já a pesquisa desenvolvida por Wang et al. (2017) verificou os efeitos do fertilizante de algas no crescimento de mudas de Malus hupehensis e a contagem de micorganismos no solo sob cultivo contínuo. Como resultado, a aplicação de fertilizantes de algas marinhas promoveu o crescimento das plantas, aumentou a taxa fotossintética, ativou enzimas antioxidativas, diminuiu a peroxidação lipídica e aumentou a concentração de nutrientes no solo.

De modo geral, a utilização de algas arribadas mistas como fertilizante orgânico, sem seleção prévia de espécies, ocasionou resultados positivos nas variáveis de crescimento de plantas analisadas. A ausência da necessidade de uma prévia seleção de espécies torna o trabalho mais rápido e viável e dá destinação a um resíduo.

Adicionalmente, o baixo custo de produção também é um fator relevante, pois aumenta a viabilidade de utilização do composto produzido.

\section{CONCLUSÕES}

A utilização de algas arribadas como fertilizante ocasionou melhoria nas variáveis de crescimento analisadas em relação às plantas crescendo em substrato com areia ou areia + húmus de minhoca. Dentre os tratamentos utilizados, aquele que proporcionou maiores valores foi a $50 \%$ da recomendação de nitrogênio (RN) em algas arribadas.

Os tratamentos com Hypnea pseudomusciformis e com Ulva fasciata apresentaram-se menos viáveis, pois além de ser necessária a separação prévia das espécies, os resultados de crescimento de plantas de girassol foram semelhantes ou inferiores aqueles que continham algas mistas.

A utilização de algas arribadas como substrato para o cultivo de plantas pode ser uma alternativa aos fertilizantes comerciais, além de reduzir custos de produção, e ser uma destinação sustentável.

\section{REFERÊNCIAS}

ADAIKALARAJ, G.; PATRIC, R. D.; JOHNSON, M.; JANAKIRAMAN, N.; BABU, A. Antibacterial potential of selected red seaweeds from Manapad coastal areas, Thoothukudi, Tamil Nadu, India. Asian Pacific Journal of Tropical Biomedicine, v. 2, n. 2, p. S1077-S1080, 2012. DOI: https://dx.doi.org/10.1016/S22211691(12)60364-5

ALOBWEDE, E.; LEAKE, J. R.; PANDHAL, J. Circular economy fertilization: Testing micro and macro algal species as soil improvers and nutrient sources for crop production in greenhouse and field conditions. Geoderma, Amsterdam, v. 334, p. 113-123, 2019.

DOI: https://dx.doi.org/10.1016/j.geoderma.2018.07.049

ARAÚJO, J. M. H. D. Algas marinhas como bioestimulantes no crescimento inicial de espécies florestais da Caatinga. $2017 . \quad 13 \mathrm{f}$. Dissertação (Mestrado em Ciências Florestais) Universidade Federal do Rio Grande do Norte, Natal, 2017.

ARAÚJO, T. V. O.; LIMA, A. D.; MARINHO, A. B.; DE LIMA DUARTE, J. M.; DE AZEVEDO, B. M.; COSTA, S. C. Lâminas de irrigação e coberturas do solo na cultura do girassol, sob condições semiáridas. Irriga, v. 17 , n. 2 , p. 126, 2012. DOI: https://dx.doi.org/10.15809/irriga.2012v17n2p126

BRASIL_CENTRO DE HIDROGRAFIA DA MARINHA. Marinha do Brasil. Disponível em: <https://www.marinha.mil.br/>. Acesso em: $14 \mathrm{de}$ agosto de 2019.

BREDEMEIER, C.; MUNDSTOCK, C. M. Regulação da absorção e assimilação do nitrogênio nas plantas. Ciência Rural, Santa Maria, v. 30, n. 2, p. 365372, 2000. DOI: http://dx.doi.org/10.1590/S010384782000000200029

LAKSHMI, T. P.; VAJRAVIJAYAN, S.; MOUMITA, M.; SAKTHIVEL, N.; GUNASEKARAN, K.; KRISHNA, R. A novel guaiane sesquiterpene derivative, guai-2-en$10 \alpha$-ol, from Ulva fasciata Delile inhibits EGFR/PI3K/Akt signaling and induces cytotoxicity in triple-negative breast cancer cells. Molecular and cellular biochemistry, The Hague, v. 438, n. 1-2, p. 123139, 2018. DOI: http:/ / dx.doi.org/10.1007/s11010-0173119-5

MALAVOLTA, E.; VITTI, G. C.; OLIVEIRA, S. A. Avaliação do estado nutricional das plantas: princípios e aplicações. 1.ed. Piracicaba: Potafos, 1997. $319 \mathrm{p}$.

NAUER, F.; CASSANO, V.; OLIVEIRA, M. C. Description of Hypnea psendomusciformis sp. nov., a new species based on molecular and morphological analyses, in the context of the H. musciformis complex (Gigartinales, Rhodophyta). Journal of Applied Phycology, Dordrecht, v. 27, n. 6, p. 2405-2417, 2015. DOI: https://dx.doi.org/10.1007/s10811-014-0488-y

PEDRINI, A. de G. (Org.). Macroalgas: uma introdução à taxonomia. 1.ed. Rio de Janeiro: Technical Books, 2010. 125 p.

SHAO, P.; QIU, Q.; XIAO, J.; ZHU, Y.; SUN, P. Chemical Stability and in vitro release properties of $\beta$-carotene in emulsions stabilized by Ulva fasciata polysaccharide. International journal of biological macromolecules, Guildford, v. 102, p. 225-231, 2017. DOI:

https://dx.doi.org/10.1016/j.ijbiomac.2017.03.186

WANG, Y.; XIANG, L.; WANG, S.; WANG, X.; CHEN, X.; MAO, Z. Effects of seaweed fertilizer on the Malus hupehensis Rehd. seedlings growth and soil microbial numbers under continue cropping. Acta Ecologica Sinica, v. 37, n. 3, p. 180-186, 2017. DOI: https://dx.doi.org/10.1016/j.chnaes.2017.01.004

ZHOU, G.; QIU, X.; ZHANG, J.; TAO, C. Effects of seaweed fertilizer on enzyme activities, metabolic characteristics, and bacterial communities during maize straw composting. Bioresource technology, Essex, v. 286, p. 121375, 2019. DOI: https://dx.doi.org/10.1016/j.biortech.2019.121375 